\title{
Intraoperative Pulmonary Tumor Embolism After Hepatectomy for Liver Carcinoma
}

Intraoperative pulmonary tumor embolism occurred during right hepatectomy for primary hepatic carcinoma. The tumor embolus produced abrupt arterial hypotension, tachycardia, an increased central venous pressure, intense cyanosis, followed by cardiac arrest. Pulmonary tumor embolism resulting from hepatic tumors is rare and has not been reported to have occurred intraoperatively. When tumor thrombosis has been detected or suspected, hepatic vascular exclusion should be considered for the prevention of intraoperative embolism.

\section{Key Words}

EMBOLISM: tumor; COMPLICATIONS: pulmonary embolism; SURGERY: hepatectomy.
From the Departments of Anaesthesiology and Surgery, University of Nantes.

Address correspondence to: Dr. Y. Blanlwil, Département d'Anesthésie et de Réanimation, Hôpital Saint-Iacques, C.H.U. de Nantes, 85, nue SaintJacques, 44035 Nantes Cédex, France.
Pulmonary tumor emboli resulting from hepatic tumors, although rare, often escape diagnosis. ${ }^{1-4}$ There are no published reports of their intraoperative occurrence. Intraoperative pulmonary embolisms are generally due to a thrombotic embolus, occasionally to an air embolus and infrequently to a fat or an amniotic embolus. We are reporting an intraoperative pulmonary tumor embolism which resulted from primary hepatic carcinoma and led to a fatal cardiac arrest.

\section{Case Report}

A 58-year-old man was admitted to the hospital with chronic fever, asthenia, weight loss of $11 \mathrm{~kg}$ in one year and painful hepatomegaly. Hepatocarcinoma with cirrhosis was diagnosed and the patient was scheduled for hepatectomy. Hepatic arteriography demonstrated the tumor in the right lobe of the liver. An inferior vena cavogram failed to show evidence of thrombosis in the vena cava, but streaks in the right suprahepatic vein wcre retrospectively interpreted as possible intravascular tumor metastases.

Preoperative examination revealed no abnormalities of the cardiovascular and respiratory systems. The chest $x$-ray, ECG, pulmonary function tests, haematological and serum biochemical studies were all normal.

The patient was premedicated with intramuscular atropine $0.75 \mathrm{mg}$ and diazepam $15 \mathrm{mg}$. After preoxygenation and $3 \mathrm{mg}$ of phenoperidine, anaesthesia was induced with thiopentone $300 \mathrm{mg}$. Endotracheal intubation was facilitated by pancuronium and controlled ventilation instituted. Anaesthesia was maintained with phenoperidine and nitrous oxide 60 per cent in oxygen. Before the incision a central venous catheter was introduced through a basilic 
vein and the central position confirmed by chest $x$-ray. A radial artery was cannulated for continuous monitoring of arterial pressure.

After thoracolaparotomy and exploration for resectability it was decided to proceed with right hepatectomy. Ligation of the right hepatic elements of the hepatic triad was carried out. A tumor thrombus located in the portal vein was extracted. After incision of the Glisson's capsule, the liver was opened by finger fracture. In the right superior hepatic vein loose tumor fragments were also found.

Right hepalectomy was performed without difficulty but immediately after mobilization of the residual liver arterial hypotension abruptly occurred (decrease from $17.3 / 10.7 \mathrm{kPa}(130 / 80 \mathrm{mmHg})$ to $9.3 \mathrm{kPa}(70 \mathrm{mmHg})$ associated with tachycardia (from 90 to $120-130$ beats $/ \mathrm{min}$.). When manipulation of the liver ceased, arterial pressure was partially restored to $13.3 / 9.3 \mathrm{kPa}(100 / 70 \mathrm{mmHg})$. However, arterial pressure subsequently fell while central venous pressure increased from 0.9 to $2.5 \mathrm{kPa}\left(9\right.$ to $\left.25 \mathrm{cmH}_{2} \mathrm{O}\right)$. Heart rate remained unchanged. During this time cyanosis was noted and persisted in spite of ventilation with 100 per cent oxygen. Ventricular fibrillation and cardiac arrest followed. Death occurred in spite of resuscitation with external cardiac massage followed by open cardiac massage.

The autopsy and microscopy examinations showed tumor embolism completely obstucting the left inferior lobar pulmonary artery. Tumor emboli were also disseminated throughout the smallest pulmonary arteries of both lungs. The heart was normal. Histologic examination of the right lobe of the liver confirmed hepatocarcinoma and cirrhosis.

\section{Discussion}

Arterial hypotension at the onset of the incident coincided with the mobilization of the residual liver. It is likely that this corresponded with the beginning of the embolism from the tumor metastases located in the superior hepatic veins, discovered during the surgical procedure. However, the second deterioration took place progressively, and the haemodynamic alterations, including hypotension, tachycardia and gradual increase of central venous pressure (CVP), were associated with profound cyanosis, in spite of a high inspired oxygen tension. Progressive tumor embolism must have been at the origin of this incident, since widespread tumor microemboli were found in both lungs at autopsy. This dissemination may also have been due in part to cardiac massage.

Intraoperative massive pulmonary tumor embolisms have been reported after nephrectomy, ${ }^{6,7}$ removal of a suprarenal carcinoma ${ }^{8}$ and examination under anaesthesia of a vaginal tumor. ${ }^{5}$ These embolisms resulted from inferior vena cava invasion and often entailed sudden cardiac arrest after an episode of hypotension. ${ }^{5,7,8}$ In the case reported by Milne, ${ }^{6}$ an identical haemodynamic profile to that of our case is described.

Sudden hypotension with tachycardia was followed by cyanosis and an increase in CVP from 0.4 to $3.1 \mathrm{kPa}$ ( 4 to $32 \mathrm{cmH}_{2} \mathrm{O}$ ) before cardiac arrest. However, pulmonary tumor embolism, though well known in hepatic cancer, have never been reported to occur during operation. Kanashima" reported tumor embolism in the right atrium after an hepatic artery ligation for hepatoma, but the incident occurred on the 22nd postoperative day and was attributed to the release of the embolus from the hepatic veins.

Although hepatic metastases from malignancies of the abdominal viscera are the most common cause of pulmonary tumor embolism, occurrences due to primary tumors of the liver are likely underestimated. The clinical features are those of acute cor pulmonale, or of sudden death, and seldom of a progressive pulmonary hypertension. ${ }^{1-4}$ Diagnosis of metastatic invasion of hepatic veins appears to be difficult but would be important for the prevention of embolism. Thus, we must pay attention to abnormalities revealed by hepatic vein radiography ${ }^{9}$ and anticipate the possibility of embolism during or after hepatectomy. In fact, tumor manipulation may promote embolism. ${ }^{5}$ The surgical technique must allow for this possibility and the patient should undergo hepatic vascular exclusion. ${ }^{10}$ Recently, two successful cases of emergency extraction of pulmonary tumor emboli using cardiopulmonary bypass have been reported. ${ }^{6.7}$ However, this technique appears to have limited applicability.

In summary, pulmonary tumor embolism occurred after hepatectomy for hepatocarcinoma. The embolism produced arterial hypotension, tachycardia, increase of CVP and intense cyanosis. When tumor thrombosis has been detected or suspected, 
hepatic vascular exclusion could be considered for the prevention of intraoperative cmbolism.

\section{Acknowledgements}

The authors gratefully acknowledge the assistance of Mrs. F. Buzelin MD, for the pathological examination, and of Mr. J. Gray for revising the translation.

\section{References}

1 Brisbane JU, Howell DA, Bonkowsky HL. Pulmonary hypertension as a presentation of hepatocarcinoma: report of a case and brief review of the literature. Am J Med 1980; 68: 466-9.

2 Burnett RA. Cor pulmonale due to tumor embolism derived from intrasinusoidal metastatic liver carcinoma. J Clin Pathol 1975; 28: 457-64.

3 Chomette $G$, Auriol $M$, Sevestre $C$, Acar $J$. Les embolies pulmonaires neoplasiques. Expressions cliniques et incidence anatomique. Ann Med Interne (Paris) 1980; 131: 217-21.

4 Myers $J D$, Mark E. Severe acute respitatory failure in a 27-year-old woman. (Case record of the Massachuserts General Hospital.) N Engl I Med 1980; 303: 1049-56.

5 Arthur DS, Stephens CA, Brummitt WM, Steward $D J$, Norman $M G$. Fatal tumor embolism during examination under anesthesia. Surgery 1973; 74 : 466-8.

6 Milne B, Cervenko FW, Morales A, Salerno TA. Massive intraoperative pulmonary tumor embolus from renal cell carcinoma. Anesthesiology 1981; 54: 253-5.

7 Akyon MG, Arslan G. Pulmonary embolism during surgery for a Wilms' tumour (nephroblastoma). Br J Anaesth 1981; 53: 903-5.

8 Todd RM. Sudden death caused by tumor embolism in a child of 4 years following operative removal of supra-renal carcinoma. Br J Surg 1952; 39 : 447-52.

9 Kanashima R. Nagasue N, Kobayashi M, Ino. $k u c h i K$. Tumor embolism in the right atrium after hepatic artery ligation for hepatoma. Jap J Surg $1977 ; 7: 246-52$.

10 Huguet C, Nordlinger B, Galopin JJ, Bloch P, Gallot $D$. Normothermic hepatic vascular exclusion for extensive hepatectomy. Surg Gynecol Obstet 1978; 147; 689-93.

\section{Résumé}

Les auteurs rapportent un cas d'embolie pulmonaire tumorale per-opératoire lors d" un hépatecromie pour hépatome. L'accident est révélé par une hypotension artérielle brutale avec une tachycardie, une augmentation de la pression veineuse centrale jusqu'd $2.5 \mathrm{kPa}$ (25 $\mathrm{cm} \mathrm{H}_{2} \mathrm{O}$ ), une cyanose intense et est suivi par un arrêt circulatoire.

Les embolies pulmonaires tumorales sont rares et cette cause d'arrêt circulatoire per-opératoire n'a jamais èté signalée. Lorsqu'une thrombose tumorale est dépistée ou suspectée au cours du bilan pré-opératoire, l'acte chirurgical doit en tenir compte et prévoir une exclusion vasculaire totale. 